\title{
A Health Disparity Study among Undergraduate Students and Graduate Students at a Historically Black College or University
}

\author{
By Steffani N. Driggins ${ }^{*} \&$ Daniel T. Hembree ${ }^{ \pm}$
}

\begin{abstract}
Our study consisted of surveying undergraduate and graduate students at a historically black college and university (HBCU) about their knowledge of certain health disparities that affect African Americans. Approval from the Allen University Institutional Review Board was granted to administer an online anonymous health disparity questionnaire to undergraduate and graduate students at Allen University. The questionnaire was administered using the community based participatory research (CBPR) methodology. The sampling criteria consisted of undergraduates enrolled in the Biological Sciences course, Biology I course, Biology II course, or Freshman Seminar course during the spring 2020 semester. The sampling also consisted of graduate students that were currently enrolled in the Dickerson-Green Theological Seminary. The sample size consisted of 114 participants that completed the online questionnaire. The data from the metabolic syndrome questionnaire was analyzed using descriptive statistics, utilizing percentages from a cross-tabulation of individual responses. Most of the participants were African American (89.4\%), female (54.9\%) and between the ages of 18 and 21 (60.5\%). Between $73 \%$ and $90.4 \%$ of the participants knew that each disease on the survey disproportionately affected African Americans. However, less than 50\% knew the risk factors of breast cancer, risk factors of cervical cancer, risk factors of prostate cancer, symptoms of prostate cancer, symptoms of sickle cell anemia and treatments for sickle cell anemia. The next phase of our study will consist of conducting a metabolic syndrome (MetS) questionnaire with the graduate students. The data, along with data from the MetS questionnaire conducted with the undergraduates in a previous study, and the health disparity questionnaire data will be used to construct health disparity educational workshops at Allen University.
\end{abstract}

Keywords: health disparities, historically black colleges and universities, African American college students

\section{Introduction}

There are several health disparities associated with African Americans. Some of the health disparities are asthma, breast cancer, cervical cancer, prostate cancer, and sickle cell anemia (U.S. Department of Health and Human Services 2020).

According to the National Health Interview Survey, African Americans had a $10.7 \%$ prevalence of having asthma (Center for Disease Control 2018). This is in comparison to Asians (4.5\%), Mexicans (5.4\%), Hispanics (6.5\%), and Caucasians $(8 \%)$. The data also indicated that African American adults had a 9.6\% prevalence of having asthma. This data is significant when compared to Asians (3.8\%), Mexicans (6.6\%), Caucasians (6.8\%), and Hispanics (7.5\%).

\footnotetext{
*Associate Professor, Department of Biology, Allen University, USA.

${ }^{ \pm}$Assistant Professor, Dickerson-Green Theological Seminary, Allen University, USA.
} 
Between 2013 and 2017, the rate of new cases of breast cancer was 128.5 per 100,000 women (National Cancer Institute 2020a). The data also indicated that African American women had the second highest rate of breast cancer, which was 124.8 per 100,000 women, outside of the rate of 131.3 per 100,000 in Caucasian women. This is in comparison to the rates among Asian/Pacific Islander women (102.9), Hispanic women (99.1), and American Indian/Alaska Native women (79.5). The data indicated that the death rate among African American women from breast cancer was 27.6 per 100,000 women as well. This rate was significantly higher than the death rate among Asian/Pacific Islander women (11.4), Hispanic women (14.0), American Indian/Alaska Native women (14.6), and Caucasian women (19.8). It is estimated that approximately 276,480 new cases of breast cancer and approximately 42,120 deaths from breast cancer will occur in 2020 in women (National Cancer Institute 2020a).

Hispanic women had the highest rate of new cases of cervical cancer between 2013 and 2017, which was 9.2 per 100,000 (National Cancer Institute 2020b). However, African American women had the second highest rate of new cases of cervical cancer which was 8.7 per 100,000 women. The rate was higher than Asian/ Pacific Islander women (6.5), Caucasian women (7.2), and American Indian/ Alaska Native women (7.9). Also, the data indicated that the death rate from cervical cancer in African American women was 3.4 per 100,000 women. This was significantly higher than the death rate in Asian/ Pacific Islander women (1.8), Caucasian (2.2), American Indian/Alaska Native women (2.5), and Hispanic women (2.6). It is estimated that 13,800 new cases of cervical cancer and an estimated 4,290 deaths from cervical cancer will occur in 2020 (National Cancer Institute 2020b).

Unfortunately, African American men had the highest rate of new cases of prostate cancer between 2013 and 2017, with a rate of 175.3 per 100,000 men (National Cancer Institute 2020c). This was in comparison to American Indian/ Alaska Native (54.6), Asian/Pacific Islander men (56.7), Hispanic men (92.0), and Caucasian men (102.3). The death rate among African American men from prostate cancer was 37.9 per 100,000 men, which was indicated in the data as well. The death rate was drastically high in comparison to Asian/Pacific Islander men (8.6), Hispanic men (15.8), Caucasian men (17.9), and American Indian/Alaska Native men (18.7). An estimated 191,930 new cases of prostate cancer and an estimated 33,330 deaths from prostate cancer is predicted to occur in 2020 (National Cancer Institute 2020c).

The Centers for Disease Control (CDC) estimates that sickle cell anemia affects approximately 100,000 Americans (Centers for Disease Control 2020). Also, the CDC estimates sickle cell anemia occurs in 1 out of 365 African American births. In addition, 1 in 13 African American babies are estimated by the CDC to be born with the sickle cell anemia trait (SCT).

Given the statistical information regarding the prevalence of asthma, breast cancer, cervical cancer, prostate cancer, and sickle cell anemia among African Americans, it is imperative to investigate the knowledge of these health issues among African American college students. Our research study was constructed to survey undergraduate students and graduate students at Allen University, a HBCU 
with a large population of African American students, about their knowledge of these health disparities. Overall, the results will provide the basis for developing an educational program to help reduce and prevent these health disparities among the undergraduate and graduate student population at Allen.

\section{Methods}

\section{Ethical Approval}

An anonymous online questionnaire on health disparities associated with African Americans was reviewed and approved by the Allen University Institutional Review Board. The questionnaire template in Google Forms was used to create the online questionnaire. The questionnaire consisted of a total of 42 questions. The first few questions on the online form consisted of the following: ethical background, age, gender, classification, major, family health history, and individual health. The questions that followed assessed the participant's knowledge regarding asthma, breast cancer, cervical cancer, prostate cancer and sickle cell anemia.

\section{Sampling Criteria and Size of Participants}

The undergraduate students that were recruited to complete the health disparity questionnaire were primarily freshman and African American. The graduate students that were recruited for the study were primarily African American. The community based participatory research (CBPR) methodology (Wallerstein and Duran 2006) was used to conduct the online questionnaire among the undergraduate students and graduate students. The undergraduate participants that participated in the study were enrolled in the Biological Sciences course, Biology I course, Biology II course, or Freshman Seminar course at Allen. The graduate participants were enrolled in the Dickerson-Green Theological Seminary at Allen. The students were invited to participate in completing the questionnaire which was administered in the spring of 2020 during their class time. The undergraduate courses were chosen because they consist of large class sizes in comparison to the upper level courses. All of the students were informed that their participation in the questionnaire was voluntary and that a written consent was required before they could complete the questionnaire. All participants were also informed that they could withdraw from completing the questionnaire at any time without any adverse consequences. Each undergraduate student that completed the questionnaire received extra credit points. The graduate students that completed the questionnaire did not receive any extra credit points. The consent form that was completed by the participants was maintained in a designated locked facility. A total of 114 participants completed the questionnaire. 


\section{Data Analysis}

The data from the online health disparities questionnaire was obtained from the participants' responses that were recorded on the Google Forms survey. The questionnaire was analyzed using descriptive statistics, utilizing percentages from a cross-tabulation of individual responses.

\section{Results}

The demographics of the participants consisted of 89.4\% African American, 2.65\% African American/Caucasian, 1.8\% Native American, 0.9\% Caucasian, $0.9 \%$ Asian, and $4.35 \%$ other (two different ethnic backgrounds were chosen). Also, $55.7 \%$ were freshman, $8.0 \%$ were sophomores, $1.8 \%$ were juniors, $1.8 \%$ were seniors and $32.7 \%$ were graduate students. A total of $54.9 \%$ of the participants were female and $45.1 \%$ were male. The age of the participants consisted of $60.5 \%$ that were between $18-21$ years, $4.4 \%$ between $22-25$ years, $1.8 \%$ between $26-29$ years, $2.6 \%$ between $30-39$ years, $5.3 \%$ between $40-49$ years, $11.4 \%$ between 50 59 years, and $14 \%$ between 60 years and older. The top disciplines among the participants consisted of $33.3 \%$ of the students that were obtaining a Master of Divinity degree, followed by an undergraduate degree in biology (18.4\%), an undergraduate degree in sports management (12.3\%) and an undergraduate degree in business $(11.4 \%)$.

There was a total of $43 \%$ of participants that were athletes in comparison to $57 \%$ that were not athletes. In regards to a healthy lifestyle, the data indicated that $36 \%$ of the participants exercised 3 to 4 times a week, $25 \%$ exercised once a week, $18 \%$ exercised 2-3 times a week, $7 \%$ exercised once a month and $14 \%$ did not exercise. In addition, the data indicated that $3.5 \%$ of the participants were current tobacco smokers, $4.5 \%$ were former tobacco smokers and $92 \%$ were non-tobacco smokers. Moreover, $29.7 \%$ of the participants ate healthy, $68.5 \%$ sometimes ate healthy, and $1.8 \%$ didn't eat healthy.

The data from the online questionnaire indicated that the graduate students had a significantly lower percentage of not having a family history of asthma, breast cancer, cervical cancer, and sickle cell anemia. The percentage for the graduate participants that did not have a family history of the diseases listed above was $13.1 \%$, in comparison to $28 \%$ among the undergraduate students. The data indicated also that there was a significantly lower percentage of a family history of asthma among the graduate participants $(9.3 \%)$, in comparison to the undergraduate participants (30\%). There was a slight difference between the number of graduate participants $(0.9 \%)$ with a family history of sickle cell anemia in comparison to the undergraduate participants (3.7\%). Interestingly, the graduate students and undergraduate students had the same percentage $(3.7 \%)$ for a family history of cervical cancer. On the other hand, the percentages for a family history of breast cancer among the graduate students $(11.1 \%)$ and undergraduate students $(13 \%)$ was not significantly different. However, the data from the questionnaire 
did indicate that the graduate students had a slightly higher rate of prostate cancer $(8.3 \%)$ in their family than the undergraduate students (5.6\%).

Figure 1. Family History of Diseases of the Undergraduate Participants and Graduate Participants that completed the Online Health Disparity Questionnaire

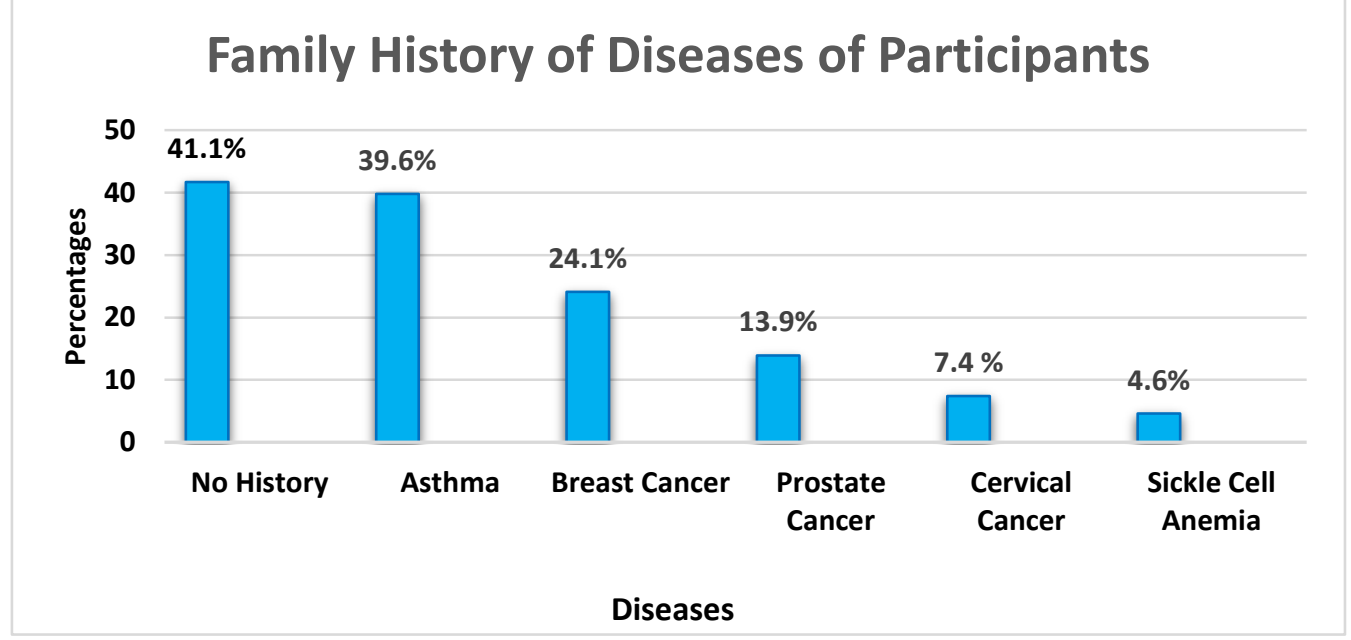

Figure 2. Individual Health History of Diseases of the Undergraduate Participants and Graduate Participants

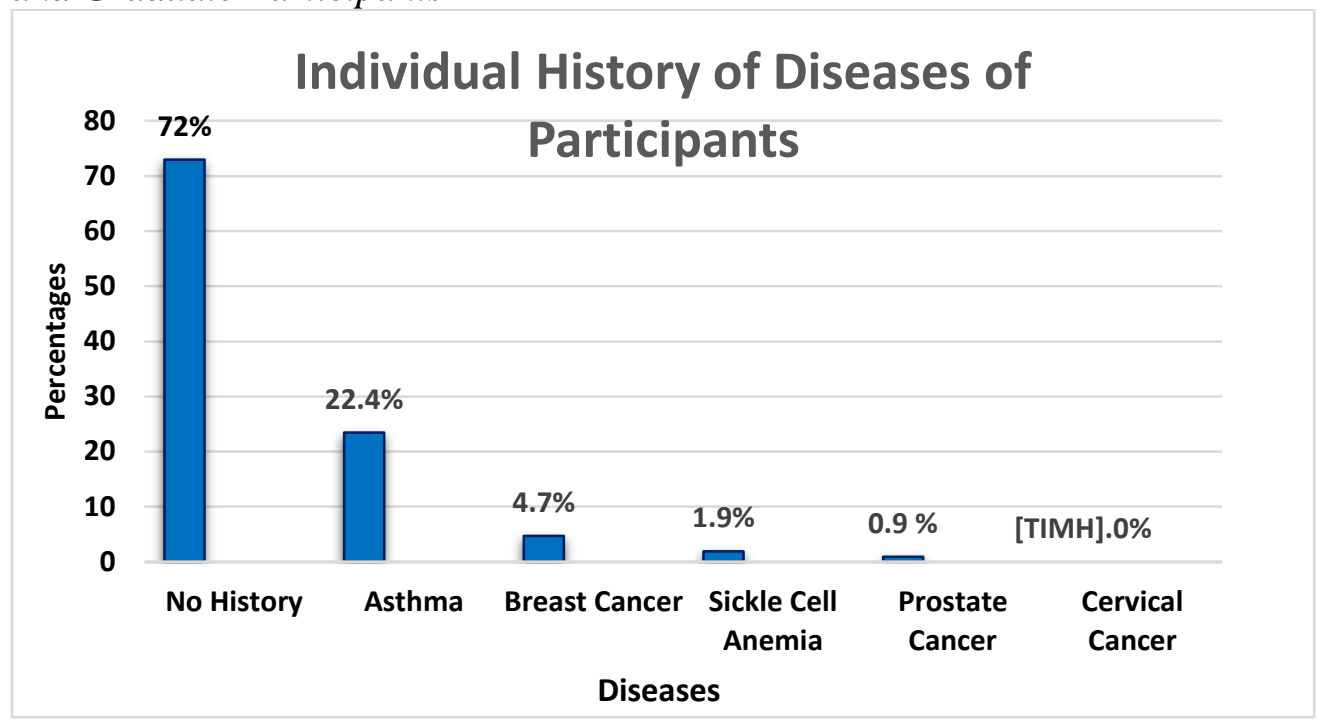

The data for the individual health history indicated that the $0.9 \%$ of a personal health history of prostate cancer was solely based on the data from the graduate students. The undergraduate participants did not indicate that they had a personal history of prostate cancer. The individual health history for breast cancer indicated that the graduate students did not have a significant higher percentage of breast cancer $(2.8 \%)$ than the undergraduate students $(1.9 \%)$. The percentage of graduate students and undergraduate students that had sickle cell anemia was the same, which was $0.93 \%$. However, the percentage of graduate students $(5.6 \%)$ that had asthma was significantly lower than the 
percentage for the undergraduate students $(16.8 \%)$. The percentage of graduate students $(27.1 \%)$ that did not have any of the health issues listed was significantly lower than the undergraduate students (44.8\%) as well.

Table 1. Correct Responses from the Undergraduate and Graduate Participants

\begin{tabular}{|c|c|c|c|c|}
\hline Conditions & Question & $\begin{array}{c}\text { Undergraduates } \\
(n=67.3 \%)\end{array}$ & $\begin{array}{l}\text { Graduates } \\
(n=32.7 \%)\end{array}$ & Overall \\
\hline \multirow{2}{*}{ Asthma } & Symptoms & $45.6 \%$ & $32.5 \%$ & $78.1 \%$ \\
\hline & Treatment & $48.2 \%$ & $29.0 \%$ & $77.2 \%$ \\
\hline \multirow{4}{*}{$\begin{array}{l}\text { Breast } \\
\text { Cancer }\end{array}$} & Cause & $39.0 \%$ & $15.9 \%$ & $54.9 \%$ \\
\hline & Diagnosis & $42.9 \%$ & $32.5 \%$ & $75.4 \%$ \\
\hline & Symptoms & $47.4 \%$ & $25.4 \%$ & $72.8 \%$ \\
\hline & Treatment & $48.2 \%$ & $28.1 \%$ & $76.3 \%$ \\
\hline $\begin{array}{l}\text { Cervical } \\
\text { Cancer }\end{array}$ & Cause & $32.7 \%$ & $36.3 \%$ & $69.0 \%$ \\
\hline $\begin{array}{l}\text { Prostate } \\
\text { Cancer }\end{array}$ & Cause & $37.2 \%$ & $31.8 \%$ & $69.0 \%$ \\
\hline \multirow{4}{*}{$\begin{array}{l}\text { Sickle Cell } \\
\text { Anemia }\end{array}$} & Cause & $43.4 \%$ & $21.2 \%$ & $64.6 \%$ \\
\hline & Shape of Cells & $32.7 \%$ & $21.2 \%$ & $53.9 \%$ \\
\hline & Protein Effected & $38.9 \%$ & $24.8 \%$ & $63.7 \%$ \\
\hline & Diagnosis & $56.6 \%$ & $31.9 \%$ & $88.5 \%$ \\
\hline
\end{tabular}

Overall, the undergraduate participants and graduate participants did know that each disease on the survey disproportionately affected African Americans. The percentage of participants that indicated that information on the questionnaire for each disease was the following: 90.4\% (asthma), 77.7\% (breast cancer), 73\% (cervical cancer), $75 \%$ (prostate cancer), and $81.3 \%$ (sickle cell anemia).

Table 2. Incorrect Responses from the Undergraduate and Graduate Participants

\begin{tabular}{|l|c|c|c|c|}
\hline Conditions & Question & $\begin{array}{c}\text { Undergraduates } \\
(\mathbf{n = 6 7 . 3 \%})\end{array}$ & $\begin{array}{c}\text { Graduates } \\
(\mathbf{n = 3 2 . 7 \%})\end{array}$ & Overall \\
\hline Asthma & Diagnosis & $43.6 \%$ & $15.5 \%$ & $59.1 \%$ \\
\hline $\begin{array}{l}\text { Breast } \\
\text { Cancer }\end{array}$ & Risk factors* & $16.6 \%$ & $31.6 \%$ & $48.2 \%$ \\
\hline $\begin{array}{l}\text { Cervical } \\
\text { Cancer }\end{array}$ & Risk factors* & $26.3 \%$ & $14.1 \%$ & $40.4 \%$ \\
\cline { 2 - 5 } $\begin{array}{l}\text { Prostate } \\
\text { Cancer }\end{array}$ & Rreatment* & $40.4 \%$ & $26.3 \%$ & $66.7 \%$ \\
\cline { 2 - 5 } & Symptoms & $36.0 \%$ & $7.2 \%$ & $43.2 \%$ \\
\hline $\begin{array}{l}\text { Sickle Cell } \\
\text { Anemia }\end{array}$ & Symptoms* & $18.2 \%$ & $23.6 \%$ & $41.8 \%$ \\
\cline { 2 - 5 } & Treatment* & $12.3 \%$ & $31.6 \%$ & $43.9 \%$ \\
\hline
\end{tabular}

*The answers to this question on the questionnaire consisted of more than one answer. However, the participants only chose one answer. The top answer that was chosen is indicated by the percentages listed for the undergraduate participants, graduate participants and overall.

The majority of the participants $(59.1 \%)$ chose an inhaling and exhaling test for the diagnosis of asthma. However, the correct answer was spirometry test and peak flow test. Only $15.5 \%$ of the participants, $5.5 \%$ undergraduate students and $10 \%$ of the graduate students selected the correct answer. 
The majority of the participants $(48.2 \%)$ only chose a family history of breast cancer as the answer for the risk factors associated with breast cancer. A total of $32.5 \%$ of the participants chose an inherited gene (mutation BRCA1 and BRCA2) as the answer. However, all of the answers listed on the questionnaire were risk factors for breast cancer.

The answer for the question regarding the risk factors for cervical cancer was all of the answers listed. However, the majority of the participants (40.4\%) chose the answer that pertained to having been diagnosed with other sexually transmitted infections. Also, the majority of the participants $(66.7 \%)$ selected surgery as a treatment for cervical cancer rather than all of the treatments listed. In addition, the question pertaining to the symptoms of cervical cancer resulted in $34.2 \%, 32.5 \%$, and $33.3 \%$ of the participants only choosing the first, second or third answer, respectively. All three answers that were listed were the symptoms. For the question regarding cervical cancer screening, both of the answers listed on the questionnaire were the correct answers. However, $66.1 \%$ of the participants only chose a Pap smear test and $33.9 \%$ only chose an HPV DNA test.

The answer regarding the risk factors associated with prostate cancer consisted of all of the answers listed on the questionnaire. However, $43.2 \%$ of the participants chose age as a risk factor for prostate cancer and $41.4 \%$ of the participants only chose a family history of prostate cancer. Also, the majority of the participants $(41.8 \%)$ only chose problems urinating as the answer to the symptoms associated with prostate cancer instead of all of the answers listed.

For the question regarding the symptoms for sickle cell anemia, all of the answers that were listed were the risk factors. However, the majority of the participants (43.9\%) only chose the following answer: low iron count, fatigue, frequent infections and episodes of pain. Also, the majority of the participants only chose one of the treatments listed for sickle cell anemia instead of all of the answers listed. Most of them (43.9\%) chose blood transfusions as the treatment for sickle cell anemia.

\section{Discussion}

The number of participants that completed the questionnaire for our health disparity study was a total of 114 . The majority of the participants were African American (89.4\%), female (54.9\%), and between the ages of 18 to $21(60.5 \%)$. Also, the majority of the participants were freshman $(55.7 \%)$ and $43.4 \%$ of the participants were athletes. A total of $32.7 \%$ of the participants were graduate students.

A mere $1 \%$ of the participants didn't indicate their gender, age, classification, ethnic background or if they were (or were not) an athlete. Also, 5.3\% of the participants did not indicate if they had a family history of the diseases listed on the survey. A total of $6.2 \%$ of the participants didn't indicate if they had any of the diseases listed on the survey as well. Even though this data was not obtained from those participants, the percentages were not significant. 
Figure 1 indicated that $41.1 \%$ of the participants didn't have a family history of the diseases listed on the questionnaire. However, a significant number of the participants that completed the questionnaire had a family history of asthma (39.6\%) in comparison to the other diseases. The data indicated that $24.1 \%$ of the participants had a family history of breast cancer, $13.9 \%$ had a family history of prostate cancer, $7.4 \%$ had a family history of cervical cancer, and $4.6 \%$ had a family history of sickle cell anemia.

The data from the questionnaire also indicated that there was a higher percentage of a family history of asthma, sickle cell anemia, or no family history of the health issues among the undergraduate participants $(67.3 \%)$ in comparison to the graduate students $(32.7 \%)$. The high percentages were due to the fact there were more undergraduate students that completed the online questionnaire than graduate students. This also contributed to a higher percentage of undergraduate students that had asthma or indicated that they did not have any of the health issues listed.

The results of our study also indicated that the participants in the study had general knowledge pertaining to asthma (Table 1). A total of $78.1 \%$ of the participants, $45.6 \%$ undergraduate students and $32.5 \%$ graduate students, knew the symptoms of asthma. The results also indicated that $77.2 \%$ of the participants, 48.2\% undergraduate students and $29.0 \%$ graduate students, knew the treatments for asthma. More than likely, this general knowledge was the result of the number of participants that had asthma (22.4\%) or had a family history of asthma (39.6\%). Some of the results of our study can be compared to a cross-sectional study that explored asthma knowledge and beliefs among African American adults in a Midwestern city (Tam-Williams et al. 2018). The study surveyed 158 African American adults. Among the participants, 38.3\% of them had been diagnosed with asthma, $78 \%$ had family members with asthma, and 59.8\% that had cared for someone with asthma. The results of their study indicated that the participants had a good general knowledge of asthma.

Figure 2 indicated that $72 \%$ of the participants did not have a personal history of the diseases listed on the questionnaire. However, $22.4 \%$ of the participants had a personal history of asthma in comparison to the other diseases listed. A personal history of breast cancer, sickle cell anemia, prostate cancer, and cervical cancer of the participants was the following: $4.7 \%, 1.9 \%, 0.9 \%$ and $0.0 \%$ respectively.

There was no significant difference in the percentage of graduate participants that had a personal history of breast cancer than the undergraduate participants. There were 3 participants that had a personal history of breast cancer. One participant was a graduate student that was 60 years or older and African American. The 2 undergraduate participants that had a personal history of breast cancer were between the ages of 18 to 21 . Both students were African American, but one undergraduate student was male, and the other undergraduate student was female.

There was, however, a lack of knowledge of the risk factors for breast cancer for all participants (Table 2). The majority of the participants only chose a family history of breast cancer instead of all of the risk factors listed. The results of our study can be compared to three other breast cancer studies that involved college 
students that were black. One study was conducted at Winston-Salem University among the campus community and the city/county community (Powell et al. 2008). The majority of the participants were African American (99\%) and educated (31\% college students; $42 \%$ college graduate and less; $14 \%$ advanced degrees and education). The study indicated that the mean score of knowledge about breast cancer was 23.25. A breast cancer study was conducted several years later in Raleigh, Durham, and Chapel Hill, North Carolina that consisted of six focus groups of African American women between the ages of 18 and 49 years (Allicok et al. 2013). A total of $33 \%$ of the participants had some college education and $53 \%$ of the participants had a college degree. The participants had little knowledge of breast cancer and thought that a family history of breast cancer could predispose a person to the disease. Sub-Saharan countries unfortunately have a high mortality rate of breast cancer in African women. This led to a study that was conducted among college students in Angola, which is a Sub-Saharan African country. In the study, the data indicated that there was a widespread lack of knowledge of the risk factors associated with breast cancer. In addition, the most known risk factor for breast cancer among the participants was a family history of breast cancer (Sambanje and Mafuvadze 2012). In Ethiopia, the incidence of breast cancer has increased. The increase influenced some researchers to conduct a questionnaire study on breast cancer among college students at the University of Gondar in Northwest Ethiopia. Their study indicated that the overall level of knowledge on breast cancer was low. Also, $75 \%$ of the participants indicated that a family history of breast cancer was a risk factor of breast cancer (Gebresillassie et al. 2018).

In our study, there was a lack of knowledge about the risk factors and treatments for cervical cancer (Table 2). All of the participants in our study only selected one risk factor for cervical cancer instead of all of the answers listed. They also only chose one treatment for cervical cancer instead of the all of the answers that were listed. The results of our study can be compared to other studies that were conducted among university students in America, South Africa and Ghana. One of the cervical cancer studies was conducted with African American women at a HBCU in the mid-Atlantic region of the United States that were between the age of 18 and 21 (Bowen-Reid et al. 2017). The results of their study indicated that the individual item analysis suggested that there were deficits in basic knowledge about cervical cancer (etiology of HPV, transmission of HPV, screening strategies and prevention strategies) among the participants. Unfortunately, cervical cancer is the second common cancer in South Africa. Thus, a cervical cancer study was conducted among university students in South Africa. The study indicated that the women that participated in the study lacked complete knowledge of cervical cancer and its risk factors (Hoque et al. 2014). Sadly, the leading cause of mortality among women in Ghana is cervical cancer. Based on this information, researchers conducted a cross-sectional cervical cancer study among college women in a university in Ghana. The study indicated that there was a lack of knowledge by the students regarding a link between smoking and cervical cancer (Abotchie and Shokar 2009). In our study, only $7.9 \%$ of the participants indicated that smoking tobacco products is a risk factor for cervical cancer. 
The percentage of a personal history of prostate cancer among the participants in our study was low, which was at a mere $0.9 \%$ (Table 2). The percentage was derived from one subject that was an African American male and a graduate student. A higher percentage of the participants (13.9\%) had a family history of prostate cancer which consisted of $8.3 \%$ of the graduate students and $5.6 \%$ of the undergraduate students. In regards to the risk factors for prostate cancer, our data indicated that $43.2 \%$ of the participants selected age for their answer, which consisted of $36 \%$ undergraduate and $7.2 \%$ graduate students. Two prostate cancer studies can be compared to our study. One study occurred at a HBCU in the southern United States and was conducted among 35 African American men that ranged in age between 18 and 34 years (Mincey et al. 2017). The participants of the study included freshmen (24\%), sophomores $(27 \%)$, juniors $(15 \%)$, seniors $(27 \%)$, and graduate students (9\%). Approximately $15 \%$ of the participants of their study had a family history of prostate cancer, which was $1.1 \%$ higher than the percentage in our study (Figure 1). Also, their study reported that their participants felt they were at a greater risk for prostate cancer because of their ethnic background. In our study, $75 \%$ of the participants knew that prostate cancer disproportionately affects African Americans. Another study was conducted among men in Austin, Texas (Ogunsanya et al. 2017). The majority of the participants were in college $(68.2 \%)$, graduate school $(11.4 \%)$, or had a second degree $(23.5 \%)$. A total of $95.9 \%$ of the participants in their study were black (African American, African or Caribbean). Overall, the knowledge of the participants in the study regarding prostate cancer was low, especially the knowledge related to risk factors. The mean correct responses of the participants consisted of $28.5 \%$. The mean knowledge score was $5.25 \% \pm 3.81$, with a median score of 5.00 .

The percentage of graduate students and undergraduate students with a personal health history of sickle cell anemia was the same. The data could possibly be associated with the fact that 1 out of 365 African Americans are estimated to have sickle cell anemia (Center for Disease Control and Prevention 2020). Also, the undergraduate and graduate participants only chose 1 risk factor for sickle cell anemia. Most of them (43.9\%) chose the following: low iron count, fatigue, frequent infections, and episodes of pain. The participants chose only 1 treatment for the treatment of sickle cell anemia as well (Table 2). The majority of them (43.8\%) chose blood transfusions as the treatment for sickle cell anemia. Two other sickle cell anemia studies can be compared to our study. One study was conducted at a North Texas campus with college students that consisted of freshman, sophomores, juniors, seniors and graduate students. Of the $15.6 \%$ of the African American students that participated in the study, $66.2 \%$ of them were knowledgeable about sickle cell anemia in comparison to $69.2 \%$ of the Caucasian students (Smith and Praetorius 2018). A non-experimental, cross sectional sickle cell anemia research study was conducted at the University of Texas at Arlington. A total of 415 college students participated that consisted of $15.7 \%$ African Americans, $16.9 \%$ Hispanics, $19.8 \%$ Asians, and 37.9\% Caucasians. The study indicated that the males and the minority participants had less knowledge about sickle cell disease than the Caucasian participants (Smith and Brownell 2018). 
Questions regarding diabetes and obesity, which are health disparities that also greatly affect African Americans, were not included on the questionnaire. This was due to the fact that data had been obtained from the undergraduate students at Allen in a previous study regarding diabetes and obesity (Driggins and Muhammad 2019). The results of study indicated that $41 \%$ of the undergraduate students had a family history of diabetes. In the study, $60.8 \%$ of the undergraduate students knew how diabetes is defined and $54.1 \%$ of them were able to identify the types of diabetes. Also, a total of $33.8 \%$ of the undergraduate students knew how obesity was defined and $17.6 \%$ knew the risk factors for obesity. The study, however, didn't include the graduate students at Allen since the focus for the study was the knowledge of the undergraduate students regarding the risk factors of metabolic syndrome.

The questionnaire did not include questions regarding high cholesterol, heart diseases or stroke, which are health disparities that affect African Americans as well. The questions were not included on the questionnaire since a previous study had been conducted with undergraduate students at Allen regarding those health disparities (Driggins and Muhammad 2019). The study indicated that $13.5 \%$ of the undergraduate students had a family history of high cholesterol, $15 \%$ had a family history of a heart attack, and $13.5 \%$ had a family history of a stroke. Also, $31 \%$ of the participants knew how high cholesterol is detected and $23 \%$ knew how high blood pressure is measured. More than half of the participants were able to identify the risk factors for high blood pressure and over half of the participants knew how a heart attack occurs. In addition, 20.9\% knew the symptoms of a heart attack, $35.1 \%$ knew when a stroke occurred, and only $25.7 \%$ knew about the symptoms of a stroke. This study did not include the graduate students at Allen since the focus for the study was the knowledge of these health disparities by the undergraduate students.

\section{Conclusion}

Analysis of the data from our health disparity study indicates that it is imperative to improve the knowledge that our undergraduate and graduate students have about the risk factors associated with breast cancer, cervical cancer, and prostate cancer. The data also indicates that the knowledge of the undergraduates and graduates regarding the treatments for cervical cancer and symptoms of prostate cancer needs to improve. Additionally, the knowledge of the symptoms and treatments for sickle cell anemia need to increase among the undergraduate and graduate students.

Even though asthma, breast cancer, cervical cancer, prostate cancer and sickle cell anemia disproportionately affect African Americans, there is a significant lack of studies by Historically Black Colleges and Universities regarding the knowledge of African American college students about these health disparities. To our knowledge, asthma studies involving questionnaires and college students at HBCU's have not been published. Only a few survey studies have been published that are related to breast cancer, cervical cancer and prostate cancer among African 
American college students at a HBCU. A few breast cancer survey studies and cervical cancer survey studies have been conducted with college students attending a university in Africa. These studies are significant because of the high rate of breast cancer and cervical cancer rates among African women, just as it is with African American women in the United States. Also, more sickle cell anemia studies need to be conducted at HBCUs. Some sickle cell anemia survey studies have been conducted with college students in the United States, but the percentage of African American participants is extremely low in both studies which is $15.6 \%$ (Smith and Praetorius 2018) and 15.7\% (Smith and Brownell 2018).

An educational intervention cervical cancer study was conducted among college students at four universities, which consisted of three historically black colleges and universities. The four universities that conducted the study were Hampton University, North Carolina Central University, West Virginia State University and Marshall University. The study indicated that the knowledge about cervical cancer among the 57 participants that completed the pre- and postintervention surveys increased significantly. The study was able to successfully improve the knowledge of the participants about HPV and cervical cancer (Staples et al. 2018). Thus, if more research regarding asthma, breast cancer, cervical cancer, prostate cancer and sickle cell anemia is conducted with African American college students at HBCU's then intervention programs could be established to educate them about these health disparities as a preventative measure.

Based on the results of our study, the next phase of our study is to administer an online metabolic syndrome questionnaire to the graduate students at Allen University to determine their knowledge of obesity, diabetes, heart disease and stroke. The data will also be compared to the data obtained from the undergraduates from a previous metabolic syndrome study (Driggins and Muhammad 2019). The data from both metabolic syndrome studies will help to determine the need to develop health disparity educational workshops that will be used to educate the undergraduate students and graduate students at Allen about health disparities that are associated with African Americans. The educational workshops will serve as preventative measures in the attempt to reduce the number of undergraduate students and graduate students from developing breast cancer, cervical cancer, prostate cancer, high blood pressure, high cholesterol, diabetes or becoming obese. The educational workshops will also help the undergraduate students and graduate students that have asthma, high blood pressure, high cholesterol, diabetes or sickle cell anemia to manage the health issue.

\section{Acknowledgments}

The authors would like to thank the faculty that allowed their students to participate in the online health disparity questionnaire. 


\section{References}

Abotchie PN, Shokar NK (2009) Cervical cancer screening among college students in Ghana: knowledge and health beliefs. International Journal of Gynecological Cancer 19(3): 412-416.

Allicock M, Graves N, Gray K, Troester MA (2013) African American women's perspectives on breast cancer: implications for communicating risk of basal-like breast cancer. Health Care Poor Underserved 24(2): 753-767.

American Society of Hematology (2016) State of sickle cell disease: 2016 report. Retrieved from: https://bit.ly/3iJTOJ2. [Accessed 7 June 2020]

American Society of Hematology. Sickle Cell Disease (2020) Retrieved from: https:// www.hematology.org/education/patients/anemia/sickle-cell-disease. [Accessed 7 June 2020]

Bowen-Reid T, Olumuyiwa D, McFarlane Oni G, Oluwafunmilayo A, Richards-McDonald L, Jones L (2017) African American college women knowledge and attitudes toward human papillomavirus (HPV) and cervical cancer screening. In Cancer Epidemiology, Biomarkers and Prevention: American Association for Cancer Research Conference 2017 26(2): A61. American Association for Cancer Research.

Centers for Disease Control and Prevention. National Center for Environmental Health (2018) 2018 national health interview survey (NHIS). Retrieved from: https://www. cdc.gov/asthma/most_recent_national_asthma_data.htm. [Accessed 25 May 2020]

Center for Disease Control and Prevention (2020) Data \& statistics on sickle cell disease. Retrieved from: https://www.cdc.gov/ncbddd/sicklecell/data.html. [Accessed 5 June 2020]

Driggins SN, Muhammad KM (2019) A population at risk: a metabolic syndrome study among African American students at a historically black college and university. Athens Journal of Health \& Medical Sciences 6(4): 231-242.

Gebresillassie BM, Gebreyohannes EA, Belachew SA, Emiru YK (2018) Evaluation of knowledge, perception, and risk awareness about breast cancer and its treatment outcome among university of Gondar students, Northwest Ethiopia. Frontiers in Oncology 8(501): 1-7.

Hoque ME, Ghuman S, Coopoosmay R, Van Hal G (2014) Cervical cancer screening among university students in South Africa: a theory based study. PloS one 9(11): e111557.

Lubeck D, Agodoa I, Bhakta N, Danese M, Pappu K, Howard R et al. (2019) Estimated life expectancy and income of patients with sickle cell disease compared with those without sickle cell disease. Jama Network Open: Hematology 2(11):1-14.

Mincey K, Turner BL, Anderson K, Maurice S, Neal R, White C (2017) Prostate knowledge, attitudes and beliefs in black college men: a qualitative study. Journal of Community Health 42(6): 1096-1101.

National Cancer Institute. Surveillance, Epidemology, and End Results Program (2020a) Cancer stat facts: female breast cancer. Retrieved from: https://seer.cancer.gov/stat facts/html/breast.html. [Accessed 23 May 2020]

National Cancer Institute. Surveillance, Epidemology, and End Results Program (2020b) Cancer stat facts: cervical cancer. Retrieved from: https://seer.cancer.gov/statfacts/ $\mathrm{html} /$ cervix.html. [Accessed 27 May 2020]

National Cancer Institute. Surveillance, Epidemology, and End Results Program (2020c) Cancer stat facts: prostate cancer. Retrieved from: https://seer.cancer.gov/statfacts/ $\mathrm{html} /$ prost.html. [Accessed 1 June 2020] 
Ogunsanya ME, Brown CM, Odedina FT, Barner JC, Adedipe TB, Corbell B (2017) Knowledge of prostate cancer and screening among young multiethnic black men. American Journal of Men's Health 11(4): 1008-1018.

Owens OL, Jackson DD, Thomas TL, Friedman DB, Hebert JR (2015) Prostate cancer knowledge and decision making among African-American men and women in the southeastern United States. International Journal of Men's Health 14(1): 55-70.

Powell FD, Bell ED, Shepperson J, Coaxum T (2008) Family breast cancer education: a model for African American women. Journal of Health Disparities Research and Practice 2(2): 17-38.

Sambanje MN, Mafuvadze B (2012) Breast cancer knowledge and awareness among university students in Angola. Pan African Journal 11(70): 1-10.

Smith M, Brownell G (2018) Knowledge, beliefs, attitudes, and behaviors regarding sickle cell disease: implications for prevention. Social Work in Public Health 33(5): 299 316.

Smith M, Praetorius RT (2018) College students' knowledge about sickle cell disease. Journal of Human Behavior in the Social Environment 29(3): 308-320.

Staples JN, Wong MS, Rimel BJ (2018) Educational intervention to improve human papilloma virus (HPV) and cervical cancer knowledge among African American college students. Gynecologic Oncology 149(1): 101-105.

Tam-Williams JB, Jones BL (2018) Closing the gap: understanding african american asthma knowledge and beliefs. Annals of Allergy, Asthma \& Immunology 121(4): 458-463.

Wallerstein NB, Dura B (2006) Using community-based participatory research to address health disparities. Health Promotion Practice 7(3): 312-323. 